\title{
Aspartylglucosaminuria in northern Norway: a molecular and genealogical study
}

\author{
Ole K Tollersrud, Øivind Nilssen, Lisbeth Tranebjærg, Olav Borud
}

\begin{abstract}
Aspartylglucosaminuria (AGU, McKusick 208400) is an autosomal recessive lysosomal storage disorder. Ninety percent of all patients are from Finland and only sporadic cases have been reported from elsewhere. In northern Norway, however, nine patients from seven families have been diagnosed with AGU. All these Norwegian patients were homozygous for the most prevalent Finnish AGU mutation ( $\left.A G U_{\text {Fin }}\right)$ and show the polymorphism uniquely associated with AGU $_{\text {Fin }}$ in Finland. Genealogical investigation of nine parents proved Finnish ancestry in all pedigrees. Therefore, AGU in Norway most likely resulted from immigration of Finnish carriers. These Finnish immigrants originated mostly from the Tornio valley area in northern Finland in a continuous immigration movement from 1700 to 1900 . The majority settled in the western part of northern Norway, leading to a "cluster" of AGU in that particular area. The Finnish immigrants. intermixed considerably with Lapps and these two ethnic origins should thus be considered as high risk groups for $A G U_{\text {Fin }}$ in northern Norway.
\end{abstract}

( $(\mathcal{F}$ Med Genet 1994;31:360-363)

Aspartylglucosaminuria (AGU, McKusick 208400 ) is an autosomal recessive storage disorder that is caused by the lack of lysosomal glycosylasparaginase (EC 3.5.1.26). ${ }^{1}$ Glycosylasparaginase is an amidase that cleaves the bond between asparagine and $\mathrm{N}$-acetylglucosamine during the ordered lysosomal degradation of $\mathrm{N}$-linked glycoproteins. ${ }^{23}$ The complete human cDNA sequence and exon/ intron organisation have recently been described. ${ }^{4-6}$ AGU resembles other lysosomal storage disorders with the formation of dilated intracellular vacuoles containing undegraded compounds, mainly Asn-glcNAc. ${ }^{7}$ Phenotypically the symptoms are detectable after 2 to 3 years of age and the disorder results in a progressive coarsening of the face with "sagging" folds of the skin, recurrent infections, and mild dysostosis multiplex. ${ }^{7}$

AGU is most prevalent in Finland with a carrier frequency of about $1 / 40 .^{8}$ Approximately $98 \%$ of the AGU alleles in the Finnish population carry a single missense mutation which results in a $\mathrm{Cys}^{163} \rightarrow$ Ser substitution $\left(\mathrm{AGU}_{\mathrm{Fin}}\right) .^{59} \mathrm{~A}$ polymorphism, Asn ${ }^{161} \rightarrow \mathrm{Arg}$, is unequivocally associated with the $A G U_{\text {Fin }}$ allele, but has no apparent effect on the enzyme function. ${ }^{910} \mathrm{AGU}_{\mathrm{Fin}}$ is restricted to Finland, but the occurrence of $A G U$ in the bordering regions of northern Sweden and northern Norway has resulted in speculation that the AGU allele was transferred there by Finnish carriers. ${ }^{11}$ In this report we show evidence that AGU in northern Norway was caused by Finnish immigrants who were carriers of $A G U_{\text {Fin }}$.

\section{Methods}

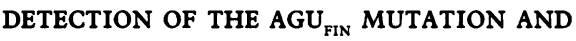
ASSOCIATED POLYMORPHISM

Genomic DNA was extracted from peripheral leucocytes using standard techniques. The $\mathrm{AGU}_{\mathrm{Fin}}$ mutation was determined by the recently described PCR based method ${ }^{12}$ : forward primer: $5^{\prime}$ tccccgggtaccgagctcgaattcgTTTTCCAATCTCCAGCCACCA 3', reverse primer: 5'TGAGCAGAAAGGATGTCACTGA 3', PCR product $219 \mathrm{bp}$. Products of EcoRI digestion were normal allele $198 \mathrm{bp}+$ $21 \mathrm{bp}, \mathrm{AGU}_{\mathrm{Fin}}$ allele $110 \mathrm{bp}+88 \mathrm{bp}+21 \mathrm{bp}$. The polymorphism was detected by DdeI digestion $^{59}$ of the same PCR product. The normal allele remained as above, while the polymorphism resulted in $126 b p+93 b p$ fragments. Digestion products were separated by standard techniques on a $2.4 \%$ agarose gel.

PCR components were $250 \mathrm{ng}$ of genomic DNA, 25 pmol of each oligodeoxynucleotide, $100 \mu \mathrm{mol} / 1 \mathrm{dNTPs}$ and 5 units Taq polymerase (BRL), $1 \times$ PCR buffer $(50 \mathrm{mmol} / 1 \mathrm{KCl}$, $10 \mathrm{mmol} / 1 \mathrm{Tris}-\mathrm{HCl}, \mathrm{pH} 8.3$, and $2.1 \mathrm{mmol} / 1$ $\mathrm{MgCl}_{2}$ ) in a total volume of $100 \mu \mathrm{l}$. PCR profile: denaturing at $94^{\circ} \mathrm{C}$ for four minutes followed by 25 cycles of $94^{\circ} \mathrm{C}$ for one minute, $63^{\circ} \mathrm{C}$ for one minute, $74^{\circ} \mathrm{C}$ for one minute, and finally extension at $74^{\circ} \mathrm{C}$ for four minutes.

\section{Studies of ethnic origin}

Ethnic origin was defined according to statements of the parents as described in a Norwegian 1930 census. ${ }^{13}$ The following definition of Finnish origin was used. (1) Both parents are Finns or (2) one of the parents is a Finn and the child has Finnish as the primary language or (3) one of the parents is a Finn and the other mixed Finnish/Norwegian or Finnish/Lappish independent of spoken language.

\section{Family studies}

The reconstruction of the pedigrees was partly carried out by the use of parish records, obtained from the Norwegian State Archives, 
The mutation in seven Norwegian AGU families

\begin{tabular}{lllll}
\hline Family & Initials & Year of birth & $A G U_{\text {Fin }}$ & Polymorphism \\
\hline $1^{*}$ & ML & 1972 & ++ & ++ \\
2 & JR & 1953 & ++ & ++ \\
2 & IR & 1958 & ++ & ++ \\
3 & OE & 1958 & ++ & ++ \\
4 & JHH & 1960 & ND & ND \\
$4^{*}$ & VH & 1968 & ++ & ++ \\
5 & TE & 1967 & ++ & ++ \\
6 & JM & 1944 & ++ & ++ \\
7 & SI & 1964 & ++ & ++ \\
\hline
\end{tabular}

The mutations for $A G U_{F i n}$ were tested by the restriction site analysis of a $P C R$ amplified fragment from whole blood as described in Methods. ${ }^{*}$ The $A G U_{\mathrm{Fin}}$ mutation of $\mathrm{ML}$ (family 1 ) and VH (family 4) have been reported previously. ${ }^{15}$ ND $=$ not determined.
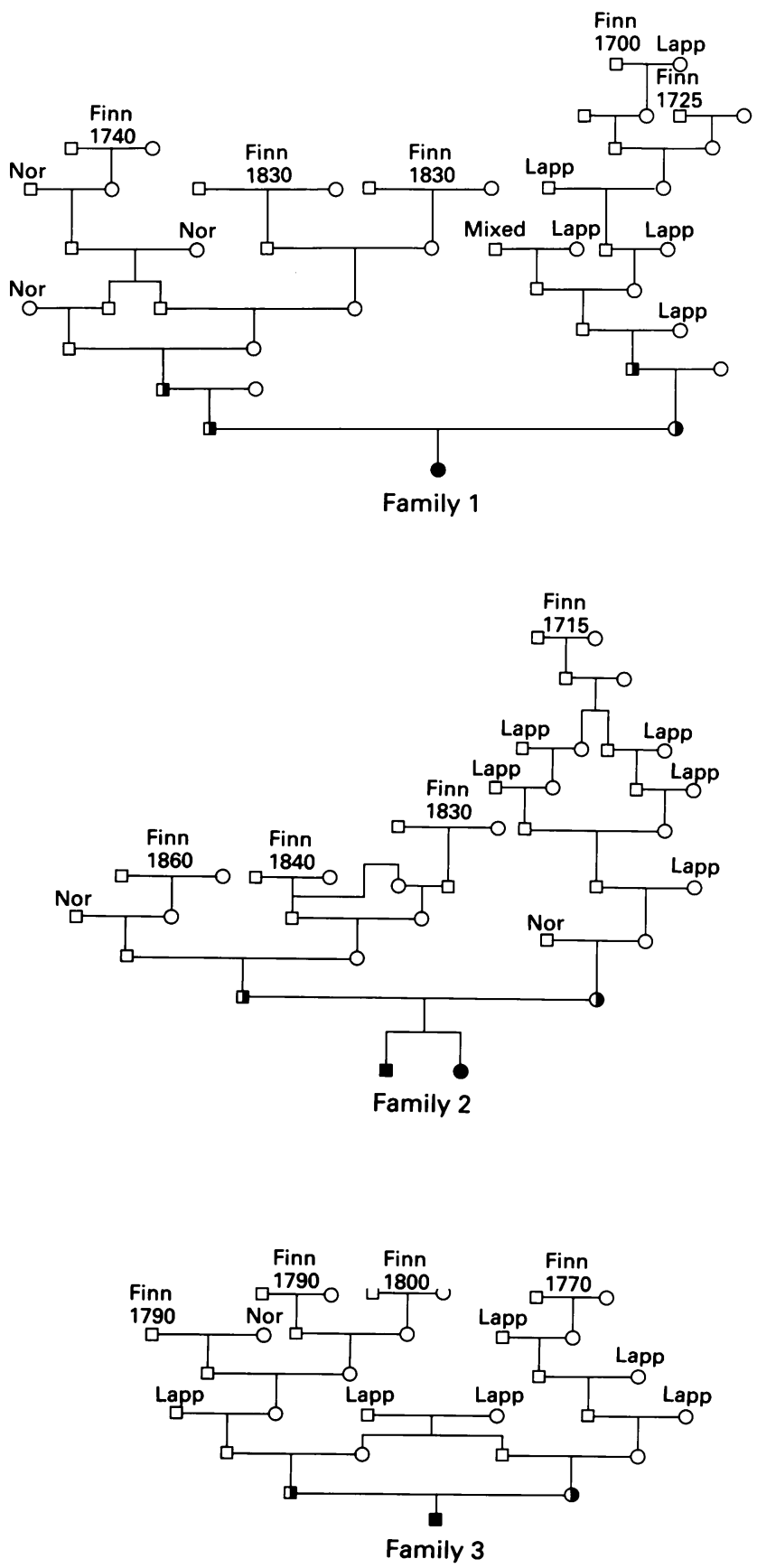

where all citizens are recorded. Data are available from 1750 onwards. Censuses for 1801 and 1865 provided information about the inhabitants of each household. The ethnic origin of the households was recorded on the 1801 census, while the ethnic origin and primary language for each person in the household were recorded in the 1865 census. However, the reliability of this information remains uncertain as the inhabitants sometimes did not want to admit Finnish ethnic origin for fear of discrimination. In these cases they might claim a Lappish origin instead, since the Finns often lived in close contact with the Lapps and mastered their language. ${ }^{14}$ Therefore, when

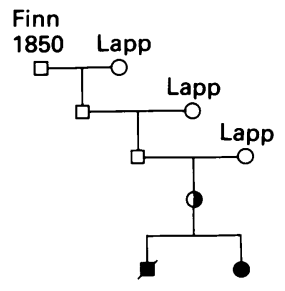

Family 4

Figure 1 Pedigrees of six Norwegian AGU families with emphasis on ethnic origin. The ethnic origin was based on parish records and censuses and traced back to 1750 or earlier. The year of immigration of Finnish ancestors are indicated when known. In family 1 the carrier status of two grandparents was known from molecular study. Nor= Norwegian. 


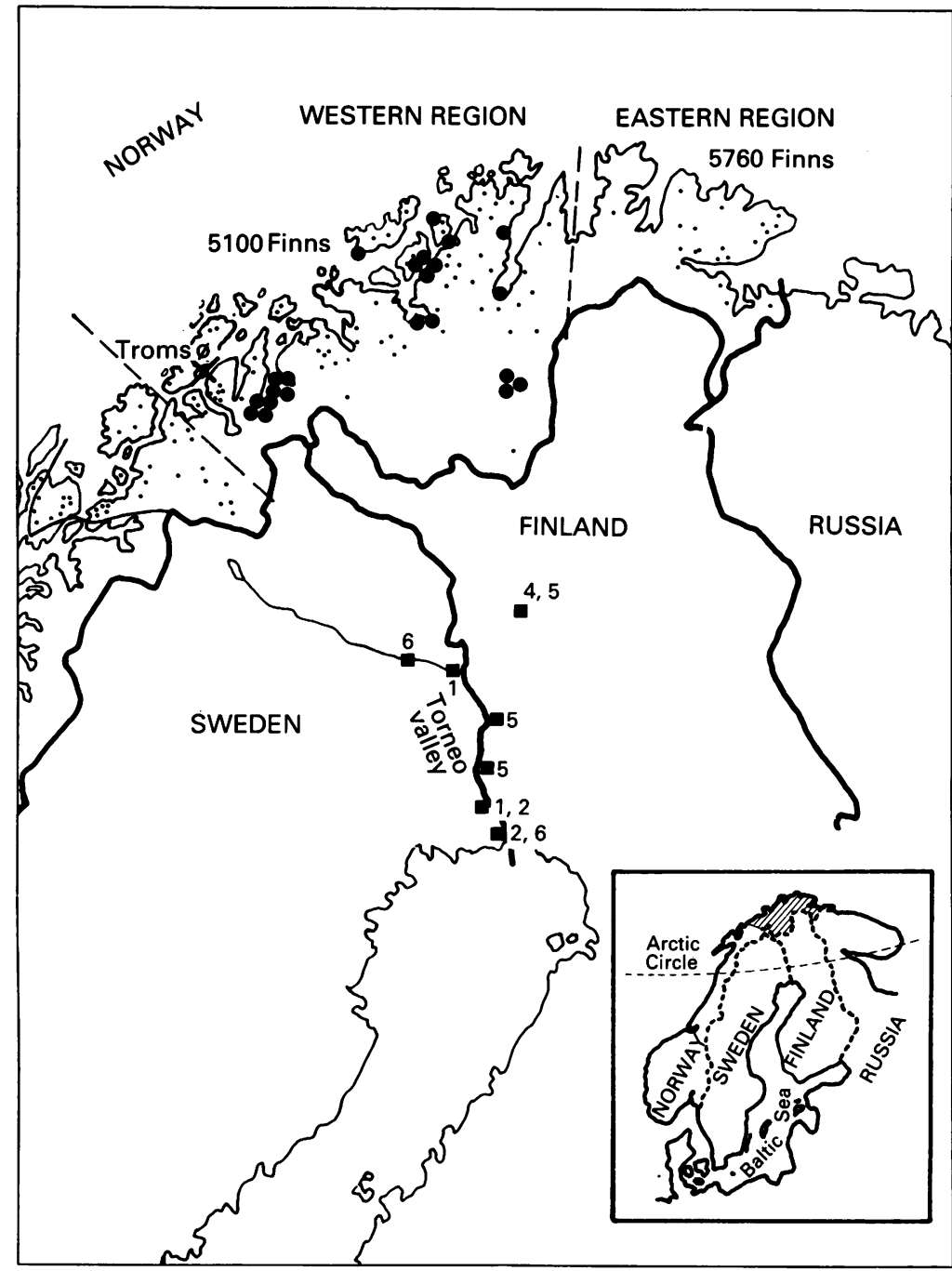

Figure 2 Birth places of grandparents of Norwegian AGU patients (dots) and those of related Finnish immigrants (squares). The families related to the respective places in Finland are indicated by numbers corresponding to those in fig 1. The distribution of the Finnish population in northern Norway was based on a 1930 census. ${ }^{13}$

possible, we tracked backwards to the original immigrant, who had to reveal his origin to church officials or for military records. In several cases Finnish and Swedish parish records were searched to confirm emigration.

\section{Results and discussion}

All Norwegian patients were homozygous for the $\mathrm{AGU}_{\mathrm{Fin}}$ mutation as shown in the table. Moreover the polymorphism uniquely associated with the $\mathrm{AGU}_{\mathrm{Fin}}$ allele in Finland ${ }^{10}$ was also present in the Norwegian AGU alleles. These results seem to prove that the AGU mutation originated from Finnish carriers.

At least nine out of 14 parents had Finnish ancestors (fig 1). All the Finnish ancestors of the AGU families were traced to the Tornio valley area at the border between northern Finland and Sweden (fig 2), but no familial interrelationship was disclosed. This suggests an early origin of $A G U_{F i n}$, in agreement with the geographical spreading of AGU within Finland. ${ }^{7}$ The present genealogical search (fig 1) indicates that the first immigrants from the Tornio valley about 300 years ago already carried the disease allele. About 400 years ago the Tornio valley was populated by a Karelian tribe, and it has been speculated that this tribe that came from the south eastern parts of Finland and partly from Russia could have carried the $A G U_{\mathrm{Fin}}$ mutation. ${ }^{16}$ AGU has not so far been reported from Russia or Estonia, but if present it might shed light on the origin of this mutation which is still not known.

Between 1700 and 1840 migration from Finland occurred predominantly to the western region of northern Norway, while migration to Norway between 1840 and 1900 was mainly to the eastern region ${ }^{14}$ (fig 2). These regions contain roughly equal numbers of Finnish descendants. ${ }^{13}$ Most of the Finnish immigrants settling in the western region of northern Norway came from the Tornio valley area (fig 2). People from more eastern areas of northern Finland mostly settled in the eastern region of northern Norway. ${ }^{17}$ There was very little admixture between the subpopulations in the eastern and western regions. All the Norwegian AGU families have their origin in the western region (fig 2 ) indicating a heterogeneous distribution of the $A G U_{\text {Fin }}$ allele within northern Finland at the time of migration.

As the ethnic origin indicated in the pedigree data (fig 1) shows, considerable mixing between Finns and Lapps has occurred. Six of the parents in fig 1 can be regarded to be of Lappish origin, while only two are of Finnish and one of Norwegian origin. Among the grandparents of AGU patients (fig 1), nine were of Lappish, six of Finnish, and three of Norwegian ethnic origin. Since $A G_{\text {Fin }}$ originated in the Finnish population, this indicates a considerable Finnish admixture in the Lapps. Nylander and Beckman ${ }^{18}$ showed a similar admixture in northern Sweden and estimated it to be in the order of 15 to $20 \%$ by means of classical serological markers. For such quantitative estimates more systematic population genetic marker studies are also required in northern Norway.

In the absence of AGU carrier screening in northern Norway it is not possible to calculate a reliable gene frequency. However, since there are seven families in a Finnish ethnic population of at least $15000,{ }^{13}$ it is possible that the prevalence of AGU among Norwegian Finns is of the same magnitude as in northern Finland, that is, about $1: 7000 .^{7}$

This study marks the first molecular and genealogical study of a "Finnish disorder" in northern Norway. The extent of this disorder indicates a need to search for other Finnish disorders as well, and also genetic marker studies to estimate the Finnish population of northern Norway more precisely.

We thank Dr L Peltonen and Dr AC Syvänen, National Public Health Institute, Helsinki, Finland for carrying out a parallel analysis for $\mathrm{AGU}_{\mathrm{Fin}}$ in some of the Norwegian AGU families.

1 Pollit RJ, Jenner FA, Merskey H. Aspartylglucosaminuria. An inborn error of metabolism associated with mental defect. Lancet 1968;ii:253-5.

2 Makino M, Kojima T, Ogushi T, Yamashina I. Studies on enzymes acting on glycopeptides. F Biochem 1968:63:18692.

3 Aronson NN, Kuranda MJ. Lysosomal degradation of Asnlinked glycoproteins. FASEB f 1989;3:2615-22.

4 Fisher KJ, Tollersrud OK, Aronson NN. Cloning and sequence analysis of a cDNA for human glycosylasparaginase. FEBS Lett 1990;269:440-4. 
5 Ikonen E, Bauman M, Grøn K, et al. Aspartylglucosaminuria: cDNA encoding human aspartylglucosaminidase 1991;10:51-8.

6 Park H, Fisher KJ, Aronson NN. Genomic structure of human lysosomal glycosylasparaginase. FEBS Lett human lysosomal

7 Aula P, Autio S, Raivio KO, Rapola J. Aspartylglucosaminuria. In: Durand P, O'Brian JS, eds. Genetic errors of glycoprotein metabolism. Milano: Edi-Ermes, Berlin Springer, 1982:122-52.

8 Syvänen AC, Ikonen E, Manninen T, et al. Convenient and quantitative determination of the frequency of a mutan allele using solid-phase minisequencing: application to aspartylglucosaminuria in Finland Genomics 1992;12:590-5.

9 Fisher KJ, Aronson NN. Characterization of the mutation responsible for aspartylglucosaminuria in three Finnish patients. F Biol Chem 1991;266:12105-13.

10 Ikonen E, Enomaa N, Ulmanen I, Peltonen L. In vitro mutagenesis helps to unravel the biological consequences of aspartylglucosaminuria mutation. Genomics 1991;11: 206-11.

11 Borud O, Torp KH. Aspartylglucosaminuria in Northern Norway. Lancet 1976;i:1082-3.

12 Nilssen $\emptyset$, Tollersrud OK, Borud O, Tranebjærg L. A simple and rapid PCR based method for $A G U_{F i n}$ determination. Hum Molec Genet 1993;2:484.

13 Lapps and Finns. The census in Norway 1 December 1930. The Statistical Central Bureau. Vol 4. Oslo: Aschehoug Press, 1933:1-10.

14 Helland A. The Norwegian land and people: Finmark region people and history. Oslo: Aschehoug Press, 1906;2:412-55.

15 Ikonen E, Aula P, Grön K, et al Spectrum of mutations in aspartylglucosaminuria. Proc Natl Acad Sci USA aspartylglucosamin

16 Autio S. Aspartylglucosaminuria. Analysis of thirty-four patients. F Ment Defic Res Monogr 1972;1:1-39.

17 Lunde AA. The history of Sor-Varanger (in Norwegian) Vadsø: Helfjord Press, 1989:104

18 Nylander PO, Beckman L. Population studies in northern Sweden. XVII Estimates of Finnish and Saamish influence. Hum Hered 1991;41:157-67. 